\title{
Effect of Deep-Fat Frying on Physicochemical Properties of Rice Bran Oil Blends
}

\author{
Monika Choudhary, Kiran Grover \\ Deptt of Food and Nutrition, Punjab Agricultural University, India
}

\begin{abstract}
Rice bran oil, non conventional oil was blended with six traditional oils in the ratio of 70:30 and 80:20 for the enhancement of its market acceptability and awareness in consumers regarding its use in cooking. Effect of deep-fat frying on these blends was studied by assessing the changes in percent fat absorption and physicochemical properties during repeated frying process (three times). The physicochemical properties like smoke point, frying temperature, viscosity, peroxide value, iodine value, acid value, free fatty acids and saponification value of six rice bran oil blends were evaluated. By comparing all the RBO blends in terms of repeated frying process and changes in physical and chemical parameters, $R B O+P O$ in both ratios was found to be the most stable frying medium up to third frying. So, this study will help the oil producing industry to find the most economically viable oil blends with desirable physicochemical properties for cooking purposes.
\end{abstract}

Keywords- Acid value, Iodine value, Peroxide value, Saponification value, Smoke point

\section{Introduction}

India is the world's largest importer and the third largest consumer of edible oils [1]. In 2007, in India alone, the annual and per capita consumption of edible oils were 11 million tones and $11.5 \mathrm{~kg}$, respectively [2]. The most common application of edible oils is in deep-frying, salad dressings and food emulsions [3]. Deep-fat frying is the cooking of food in pre-heated deep oil/fat at a high temperature of 150 to $190^{\circ} \mathrm{C}$ [4]. Fried foods have desirable flavor, color, and crispy texture, which make deep-fat fried foods very popular to consumers [5].

The food value of the edible oils depends on the physical and chemical properties [6]. Deep-fat frying changes the physical and chemical properties of oil due to formation of non -volatile compounds. Non volatile compounds affect flavor stability and quality and texture of fried foods during storage [5]. A wide range of vegetable oils is available in the market. However, some vegetable oils are not up to standards to meet consumer satisfaction in terms of their physicochemical properties and stability of the food products [7]. To improve the fat/oil functionalities and thus optimize their application in food products, direct blending of fats/oil is the method of choice as it is considered to be a cheap and non destructive technique [8,9]. Blending of vegetable oils is gaining popularity due to its advantages like to improve thermal stability, oxidative stability, and nutritional benefits. Blending of oil with rice bran oil (RBO) has been found to improve the stability of the blend during frying and storage [10].

RBO is nutritionally superior oil compared to other common vegetable oils and India is the second largest producer of crude rice bran oil in the world [11]. RBO has high levels of phytosterols, gamma-oryzanol, tocotrienols as well as tocopherols and it extends the shelf - life of snack foods. The high oxidative stability of RBO makes it preferred oil for frying and baking applications [10]. The saturated, mono saturated and poly saturated fatty acids in RBO are in the ratio of approximately 1:2.2:1.5 and the major fatty acid compositions are not influenced by storage temperature, although linolenic acid level decrease by approximately 50 percent during storage [12]. Hence, the present study was designed to investigate the effect of deep-fat frying on physicochemical properties of rice bran oil blends.

\section{Materials and Methods}

The raw ingredients for deep frying, refined rice bran oil (RBO) and other refined vegetable oils viz., Olive oil (OO), groundnut oil (GO), soybean oil (SOO), sunflower oil (SO), mustard oil (MO) and palm-olein oil (PO) were purchased from local markets. All the analytical and GC grade chemicals and solvents used were supplied by Himedia (Mumbai, India).

\subsection{Preparation of blends}

A $100 \mathrm{ml}$ mixture of RBO and other vegetable oil were placed in duplicate in 250-ml beakers for each blend and were mixed by using a mechanical stirrer at $180 \mathrm{rpm}$ for $15 \mathrm{~min}$. Blends of rice bran oil viz. $\mathrm{RBO}+\mathrm{OO}, \mathrm{RBO}+\mathrm{GO}, \mathrm{RBO}+\mathrm{SOO}, \mathrm{RBO}+\mathrm{SO}, \mathrm{RBO}+\mathrm{MO}$ and $\mathrm{RBO}+\mathrm{PO}$ were prepared in two ratios i.e., 80:20 and 70:30 [13]. 
The selection of two ratios i.e. 80:20 and 70:30 was based on recommendations given by Prevention of Food Adulteration Act (PFA) (1954) [14]. According to PFA 4th Amendment Rules 1992, blending of any two vegetable oils (wherein the component oil used in the admixture is not less than 20\%) has been permitted.

\subsection{Frying process}

Vegetable Pakoda (a traditional snack in India) was prepared in the blended oils using $100 \mathrm{~g}$ raw wet materials in $500 \mathrm{~g}$ of oil. The stainless steel pan used for frying had an area of $121 \mathrm{~m}^{2}$ and a depth of $12.5 \mathrm{~cm}$. Deep frying was done for three times and fat absorption and physicochemical properties of blended oils were analyzed after each frying i.e., First, second and third respectively.

\subsection{Physical parameters}

Viscosity of blended oil was recorded after each frying with the help of Viscometer (Patent no: 688/Del/85). Smoke point and frying temperature were determined according to the AOCS [15].

\subsection{Chemical parameters}

Peroxide value, iodine value, saponification value, acid value and free fatty acids of the blended oils were determined by using AOAC [16] methods.

\subsection{Statistical analysis}

All the determinations were carried out in triplicate and the results are given in mean \pm standard error. The mean, standard error, percentages, one way analysis of variance (CRD), CD value and their statistical significance was ascertained using a computer program package (CPCS1).

\subsection{Percent fat absorption of blended oils}

\section{Results}

In rice bran oil blends (70:30), minimum absorption of $\mathrm{RBO}+\mathrm{GO}(4.3 \%)$ was found in vegetable pakoda followed by $\mathrm{RBO}+\mathrm{OO}(6.0 \%), \mathrm{RBO}+\mathrm{SO}(7.4 \%), \mathrm{RBO}+\mathrm{MO}(8.0 \%), \mathrm{RBO}+\mathrm{SOO}(8.5 \%)$ and $\mathrm{RBO}+\mathrm{PO}$ $(10.0 \%)$ (Table1). Similarly in blended oils prepared in the ratio of 80:20, minimum absorption of RBO+GO (6.2\%) and maximum absorption of RBO+PO (10.6\%) was found in the vegetable pakoda (Table 1). After second frying absorption of all the blended oils $(70: 30,80: 20)$ increased significantly $(\mathrm{p} \leq 0.05)$ whereas after third frying there was a significant $(\mathrm{p} \leq 0.05)$ decline in the absorption rate except in the RBO+SO in the both ratios. As the number of fryings and the frying temperature increase, the amounts of polymers increased [17]. Polymers cause higher oil absorption of foods and the oil rich in linoleic acid is more easily polymerized during deep-fat frying than the oil rich in oleic acid [18].

\subsection{Physical parameters}

\subsubsection{Changes in smoke point, frying temperature and viscosity:}

The smoke point, which is the temperature at which a fat or oil produces a continuous wisp of smoke when heated, was $200^{\circ} \mathrm{C}$ and above for all the blended oils except RBO+SO $\left(188-190^{\circ} \mathrm{C}\right)$ and $\mathrm{RBO}+\mathrm{PO}(180-$ $184^{\circ} \mathrm{C}$ ) in the both ratios. RBO+GO had highest smoke point i.e., 204 and $202^{\circ} \mathrm{C}$ in the ratio $70: 30$ and 80:20 respectively (Table 2). After second and third frying, a significant $(\mathrm{p} \leq 0.05)$ decline was observed in the smoke point of all blended oils of both ratios. The smoke point of RBO+GO (70:30) and RBO+PO (80:20) showed the minimum percent decrease i.e., 4.9 and 3.3 respectively after second frying whereas after third frying, $\mathrm{RBO}+\mathrm{PO}$ (70:30) and RBO+SO (80:20) showed the minimum percent decrease in the smoke point i.e., 9.8 and 10.1 respectively. The maximum percent decrease in the smoke point was showed by $\mathrm{RBO}+\mathrm{OO}$ in the both ratios after third frying i.e., 15.0(70:30) and 13.0(80:20).

A significant $(\mathrm{p} \leq 0.05)$ increase was observed in frying temperature of all $\mathrm{RBO}$ blends in the both ratios i.e., 70:30 and 80:20 after second and third frying respectively. Deep-frying temperature should not exceed 180 ${ }^{\circ} \mathrm{C}$ as high frying temperature accelerates thermal oxidation and polymerization of oils [19]. The results showed that $\mathrm{RBO}+\mathrm{GO}$ and $\mathrm{RBO}+\mathrm{SO}$ in both ratios had frying temperature below $180^{\circ} \mathrm{C}$ up to second frying (Table 2). After third frying, $\mathrm{RBO}+\mathrm{SO}$ also showed the highest percent increase in the frying temperature in the both ratios i.e., $9.2(70: 30)$ and $10.6(80: 20)$ whereas the lowest percent increase was showed by RBO+SOO in the both ratios i.e., 3.2 (70:30) and $2.1(80: 20)$.

With respect to viscosity, $\mathrm{RBO}+\mathrm{OO}$ had higher (40-41CST) and RBO+SO had lower (31-32 CST) values than other blended oils in both ratios (Table 3$)$. After frying, a significant $(\mathrm{p} \leq 0.05)$ increase was observed in the viscosities of all blended oils. After first frying, the maximum percent increase was observed in the viscosity of RBO+MO (70:30) and RBO+SO (80:20) i.e., 5.4 and 6.5 respectively. RBO+SO also showed the highest percent increase in the viscosity after third frying i.e., 21.9 and 22.6 in the ratio of 70:30 and 80:20 respectively whereas the lowest percent increase was observed in the viscosity of $\mathrm{RBO}+\mathrm{OO}$ in the both ratios. 


\subsection{Chemical parameters}

\subsubsection{Changes in peroxide value (PV)}

Peroxide value is a measure of oxidation during storage and the freshness of lipid matrix. In addition, it is a useful indicator of the early stages of rancidity occurring under mild condition and it is a measure of the primary lipid oxidation products. So, greater the PV, the more will be the rate of oxidation of the oil [20]. The changes in the PVs of selected oil blends during deep-frying are given in Table 4. It was observed that PV increased significantly $(\mathrm{p} \leq 0.05)$ during deep frying in the experimental RBO blends. At fresh conditions, the minimum PV was observed in $\mathrm{RBO}+\mathrm{OO}$ i.e., $0.53 \mathrm{meq} / \mathrm{Kg}(70: 30)$ and $0.33 \mathrm{meq} / \mathrm{Kg}(80: 20)$ whereas the maximum $\mathrm{PV}$ was found in $\mathrm{RBO}+\mathrm{MO}$ i.e., $1.73 \mathrm{meq} / \mathrm{Kg}(70: 30)$ and $\mathrm{RBO}+\mathrm{SOO}$ i.e., $1.38 \mathrm{meq} / \mathrm{Kg}(80: 20)$. By comparing both ratios, it was found that $\mathrm{RBO}+\mathrm{OO}$ in the ratio of 70:30 showed the highest percent increase $(53.1 \%)$ in the PV whereas the lowest percent increase was recorded in RBO+PO (18.3\%) and RBO+MO $(18.8 \%)$ after first frying. In the ratio of 80:20, the highest and the lowest percent increase was observed in $\mathrm{RBO}+\mathrm{SOO}(9.8 \%)$ and $\mathrm{RBO}+\mathrm{PO}(17.3 \%)$ respectively. After second frying, again $\mathrm{RBO}+\mathrm{OO}$ showed the highest percent increase in the PV i.e., 77.3 and 81.7 whereas the lowest percent increase in PV was observed in RBO+PO i.e., 31.0 and 36.4 respectively in the ratio of $70: 30$ and 80:20. In contrast, after third frying, RBO+GO showed the least percent increase in the PV i.e., 55.9 and 66.9 in the ratio of 70:30 and 80:20 respectively. So, on the basis of percent increase in the PV, $\mathrm{RBO}+\mathrm{PO}$ and $\mathrm{RBO}+\mathrm{GO}$ were the most stable blends up to third frying in the both ratios.

\subsubsection{Changes in iodine value (IV)}

Iodine value is an index of the unsaturation, which is the most important analytical characteristic of oil [21]. The data on changes in the IV of the rice bran oil blends during deep frying are presented in Table 4. It was observed that IV decreased significantly $(\mathrm{p} \leq 0.05)$ during deep frying in the experimental RBO blends. At fresh conditions, the maximum IV was observed in RBO+SO i.e., 117.0g (70:30) and 118.9g (80:20) whereas the minimum IV was found in RBO+PO i.e., 107.3g (70:30) and 107.0g (80:20). By comparing both ratios, it was found that $\mathrm{RBO}+\mathrm{OO}$ in the ratio of 80:20 showed the highest percent decrease (5.9\%) in the IV whereas the lowest percent decrease was recorded in RBO+MO (0.4\%) and $\mathrm{RBO}+\mathrm{PO}(1.1 \%)$ after first frying. In the ratio of 70:30, the highest and the lowest percent decrease was observed in RBO+SO $(5.9 \%)$ and $\mathrm{RBO}+\mathrm{OO}(0.8 \%)$ respectively. Besides, the percent decrease in IV was also at lower side in $\mathrm{RBO}+\mathrm{SOO}(1.1 \%)$ and $\mathrm{RBO}+\mathrm{PO}$ $(1.6 \%)$ in the ratio of $70: 30$ after first frying.

After second frying, again RBO+OO (80:20) and RBO+SO (70:30) showed the highest percent decrease in the IV i.e. 8.2 and 8.5 respectively whereas the lowest percent decrease in IV was observed in $\mathrm{RBO}+\mathrm{GO}(80: 20)$ and $\mathrm{RBO}+\mathrm{OO}(70: 30)$ i.e. 3.2 and 2.2 respectively. RBO+MO (80:20) and RBO+SOO (70:30) also showed less percent decrease (i.e. 3.2 and 2.6 respectively) in the IV after second frying. After third frying, the highest percent decrease in the IV was recorded in RBO+SO (10.4\%) followed by RBO+OO (9.5\%) in the ratio of 80:20 whereas lowest percent decrease was observed in RBO+PO (4.5\%). Similar trends were observed in the ratio of 70:30, the highest and the lowest percent decrease was found in $\mathrm{RBO}+\mathrm{SO}(10.7 \%)$ and $\mathrm{RBO}+\mathrm{PO}(2.7 \%)$ respectively. Interestingly, it was also found that the percent decrease in the IV of RBO+PO after third frying was lower than the percent decrease after second frying in both ratios.

\subsubsection{Changes in acid value (AV) and free fatty acids (FFA)}

Acid value is a measure of the free fatty acids in the oil. Normally, fatty acids are found in the triglyceride form, however, during processing the fatty acids may get hydrolyzed into free fatty acid. The higher the AV found, the higher the level of FFA which translates into decreased oil quality. Acceptable levels for all oil samples should be below $0.6 \mathrm{mg} \mathrm{KOH} / \mathrm{g}$ (measured in potassium hydroxide per gram) [22]. The changes in the AVs of selected oil blends during deep-frying are shown in Table 5. It was observed that AV increased significantly $(\mathrm{p} \leq 0.05)$ during deep frying in the experimental RBO blends. At fresh conditions, the minimum $\mathrm{AV}$ was observed in $\mathrm{RBO}+\mathrm{OO}(70: 30)$ and $\mathrm{RBO}+\mathrm{SOO}(80: 20)$ i.e., $0.19 \mathrm{mg} \mathrm{KOH} / \mathrm{g}$ whereas the maximum $\mathrm{AV}$ was found in $\mathrm{RBO}+\mathrm{PO}$ i.e., 0.42 and $0.37 \mathrm{mg} \mathrm{KOH} / \mathrm{g}$ in the ratio of 70:30 and 80:20 respectively. After first and second frying, in the ratio of 70:30, RBO+PO did not show any change in the AV whereas RBO+SO (17.9\%) and $\mathrm{RBO}+\mathrm{MO}(15.2 \%)$ showed least percent increase in the AV after first and second frying respectively. Surprisingly, after third frying AV of RBO+GO (70:30) reduced to the initial value $(0.37 \mathrm{mg} \mathrm{KOH} / \mathrm{g})$ which was recorded at fresh conditions whereas $\mathrm{RBO}+\mathrm{PO}(70: 30)$ showed the lowest percent increase $(25.0 \%)$ in the $\mathrm{AV}$ after third frying. RBO+PO also showed the lowest percent increase (12.1\%) in the AV after third frying in the ratio of 80:20.

The changes in free fatty acid (FFA) values are expressed as percent oleic acid. The percentage of FFA were found to be the lowest in $\mathrm{RBO}+\mathrm{OO}(70: 30)$ and $\mathrm{RBO}+\mathrm{SOO}(80: 20)$ i.e., 0.09 and the highest percentage of FFA was found in RBO+PO (70:30) i.e., 0.21 at fresh conditions (Table 5). There were significant differences $(\mathrm{p} \leq 0.05)$ among the frying media in terms of FFA. The changing trend in the percent increase of 
FFA in the RBO blends was similar to the percent increase in the AV after fryings. RBO+PO in the both ratios consistently showed the lowest percent increase in FFA formation up to third frying. Interestingly, after third frying FFA of RBO+PO reduced to 0.16 percent from its initial value $(0.19 \%)$ by 18.8 percent.

\subsubsection{Changes in saponification value (SV)}

Saponification value is an indication of the molecular weights of triglycerides in oil. It is inversely proportional to the average molecular weight or chain length of the fatty acids [23]. Therefore, shorter the average chain length (C4-C12) the higher is the SV [24]. There were significant differences $(\mathrm{p} \leq 0.05)$ among the RBO blends in terms of SV. The highest SV was found in RBO+PO i.e., $329.5 \mathrm{mg} \mathrm{KOH} / \mathrm{g}(70: 30)$ and 285.6 $\mathrm{mg} \mathrm{KOH} / \mathrm{g}(80: 20)$ at fresh conditions which significantly $(\mathrm{p} \leq 0.05)$ decreased to 133.5 and $108.3 \mathrm{mg} \mathrm{KOH} / \mathrm{g}$ after third frying (Table 6). The lowest SV was found in RBO+SOO i.e., $184.1 \mathrm{mg} \mathrm{KOH} / \mathrm{g}(70: 30)$ and 174.5 $\mathrm{mg} \mathrm{KOH} / \mathrm{g}(80: 20)$ at fresh conditions which significantly $(\mathrm{p} \leq 0.05)$ decreased to 65.3 and $76.5 \mathrm{mg} \mathrm{KOH} / \mathrm{g}$ after third frying (Table 6). By comparing both ratios, it was found that $\mathrm{RBO}+\mathrm{GO}(70: 30)$ and $\mathrm{RBO}+\mathrm{OO}(80: 20)$ showed the lowest percent decrease (15.4 and $5.8 \%$ respectively) in the SV whereas the highest percent decrease was recorded in $\mathrm{RBO}+\mathrm{SOO}(70: 30)$ and $\mathrm{RBO}+\mathrm{GO}(80: 20)$ i.e., 29.0 and 33.0 percent respectively after first frying. After second frying, again $\mathrm{RBO}+\mathrm{OO}$ showed the lowest percent decrease in the SV i.e., 32.7 and 23.7 percent whereas the highest percent decrease in SV was observed in $\mathrm{RBO}+\mathrm{SOO}(70: 30)$ and RBO+GO(80:20) i.e., 41.3 and 48.2 percent respectively. In contrast, after third frying, RBO+GO showed the least percent decrease in the SV i.e., 55.9 and 66.9 in the ratio of 70:30 and 80:20 respectively. Overall, $\mathrm{RBO}+\mathrm{OO}$ in the both ratios showed the lowest percent decrease in the SV up to third frying.

\section{Discussion}

Results of the study revealed that product prepared in RBO blends showed an increase in the fat absorption after second frying. This was consistent with findings from previous studies showing that the amounts of polymers increased with an increase in the number of fryings and the frying temperature. These polymers cause higher oil absorption of foods [17]. After third frying, the highest absorption of RBO+SO and the lowest absorption of RBO+GO in both ratios could be due to the presence of linoleic acid and oleic acid respectively. The oil rich in linoleic acid is more easily polymerized during deep-fat frying than the oil rich in oleic acid [18]. Smoke point of all RBO blends was $200^{\circ} \mathrm{C}$ and above except RBO+SO and RBO+PO. This meets the standard requirement for frying oils which should have a smoke point above $200^{\circ} \mathrm{C}$ [22]; an indication that these vegetable oils are suitable for frying purposes. After second and third frying, a significant $(\mathrm{p} \leq 0.05)$ decline was observed in the smoke point of all blended oils of both ratios. This could be due to the presence of minor components especially FFA. FFA have a direct lowering effect on the smoke point [25].

According to the opinion of the Working Group of Regional Food Chemistry Experts and the German Federal Public Health Department of 1991, the smoke point of a cooking oil must be at least $170{ }^{\circ} \mathrm{C}$ and must not differ from the temperature of the fresh oil by more than $50{ }^{\circ} \mathrm{C}$ so that the oil can still be classified as usable. The findings of the present study were in line with this statement as all the RBO blends except RBO+PO had an appropriate smoke point $\left(\geq 170^{\circ} \mathrm{C}\right)$ up to third frying in the both ratios. In terms of viscosity, the highest percent increase was showed by RBO+SO. These increases were evidence of the thermal effect, the formation of polymeric compounds and a tendency toward foaming during frying periods [26]. Previous studies have also reported that polymers accelerate further degradation of the oil and increase the oil viscosity [27].

In terms of chemical parameters, there was a steady increase in PV of RBO blends during frying, but this increase was seen to be the least. After each frying, PV of all blends were in agreement with the maximum Codex standard PV $\left(10\right.$ meq $\left.\mathrm{O}_{2} / \mathrm{Kg}\right)$ for vegetable oil deterioration. The nutritional contribution of the three minor components of tocopherol, tocotrienols and $\gamma$-oryzanol in rice bran oil blends may have conferred this greater oxidative stability [28]. The highest and the lowest percent increase in PV was shown by RBO+OO and $\mathrm{RBO}+\mathrm{PO}$ respectively. Similar changes in PVs of oils were reported in previous deep -fat frying studies [29,30]. By comparing both ratios, it was found that $\mathrm{RBO}+\mathrm{SO}$ and $\mathrm{RBO}+\mathrm{PO}$ had maximum and minimum IV respectively. The greater the degree of unsaturation (or high IV), the more rapid the oil tends to be oxidized, particularly during deep-fat frying [31]. The highest and the lowest percent decrease in the IV was also recorded in $\mathrm{RBO}+\mathrm{SO}$ and $\mathrm{RBO}+\mathrm{PO}$ respectively after third frying in the both ratios. Rastogi et al [32] also reported a significant decrease in IV of cooking oils after deep -frying. Although the highest percent decrease in IV was shown by $\mathrm{RBO}+\mathrm{SO}$, the protective role of the natural antioxidants induced by the presence of rice bran oil (i.e., Oryzanol, tocopherols) resulted in a smaller decrease in the double bonds [10].

All RBO blends presented in this study had acceptable AV after frying as per Codex Standard [33] (0.6 $\mathrm{mg} \mathrm{KOH} / \mathrm{g}$ ). Amongst all RBO blends, RBO+PO showed the lowest percent increase in the AV after third frying in the both ratios. As discussed above, the percentage of FFA was found to be the lowest in $\mathrm{RBO}+\mathrm{OO}$ (70:30) and RBO+ SOO (80:20) and the highest percentage of FFA was found in RBO+PO (70:30) at fresh conditions. But after frying, RBO+PO showed the lowest percent increase in FFA formation. The percent 
changes in the FFA formation in the RBO blends were similar to the percent changes in the AV after fryings. The significant increase $(p \leq 0.05)$ in free fatty AV may be due to the presence of an active lipase in rice bran, which upon milling is activated and quickly begins to hydrolyze triglycerides into FFA [34]. Similar increase in free fatty acid formation after deep- fat frying was also reported by Serjouie et al. [30]. A significant decrease $(\mathrm{p} \leq 0.05)$ in SV of all RBO blends was observed after frying. Onigbogi \& Sowunmi [35] also observed a significant decrease in SV of oils after deep-fat frying. A consistent lowest percent decrease in the SV was shown by $\mathrm{RBO}+\mathrm{OO}$ in the both ratios up to third frying.

\section{Conclusion}

The quality and properties of the oils and blends were evaluated through this study using different parameters. It was concluded that minimum absorption of RBO+GO (both ratios) was found in the product prepared using deep frying. By comparing all the RBO blends in terms of repeated frying process and changes in physical and chemical parameters, $\mathrm{RBO}+\mathrm{PO}$ in both ratios was found to be the most stable frying medium up to third frying. Significant $(p \leq 0.05)$ changes were observed in physical as well as chemical parameters of all RBO blends during deep- fat frying but values of all the parameters were within the suggested ranges. This could be due to the nutritional characteristics of rice bran oil. So, this study will help the oil producing industry to find the most economically viable oil blends for cooking purposes, with maximum nutrition as well as desirable physicochemical properties. As India is the second largest producer of RBO, blending of traditional oils with this nonconventional oil is a good choice by which we can manufacture edible oils of good characteristics and ensure their quality. The food value of the oils and blends can also be predetermined to provide the safest food for consumers.

\section{References}

[1]. P. Ramesh and M. Murughan, Edible oil consumption in India. Asia and Middle East Food Trade Journal, 3, $2008,8-9$.

[2]. MOFPI. (2011). Ministry of Food Processing of India. http://mofpi.nic.in/Content Page.aspx?CategoryId=687

[3]. K.P. Ghosh, D. Chatterjee and P. Bhattacharjee, Alternative methods of frying and antioxidant stability in soybean oil. Advance Journal of Food Science and Technology, 4, 2012, 26-33.

[4]. E. Choe and D.B. Min, Chemistry of deep-fat frying oils. Journal of Food Science, 72, 2007, 77-86.

[5]. G. Boskou, F.N. Salta, A. Chiou, E. Troullidou and N.K. Andrikopoulos, Content of trans, trans-2,4-decadienal in deep-fried and pan-fried potatoes. European Journal of Lipid Science and Technology, 108, 2006, 109-115.

[6]. H. Shibasaki and T. Yamane, Avoidance of solidification of sesame oil at low temperature by self interesterification with immobilized lipase. Bioscience Biotechnology Biochemistry, 64, 2000, 1011-15.

[7]. J. Reyes-Hernandez, E. Dibildox-Alvarado, M. Charo-Alonso and J. Toro-Vazquez, Physicochemical and rheological properties of crystallized blends containing trans -free and partially hydrogenated soybean oil. Journal of American Oil Chemist's Society, 84 , 2007, 1081-93.

[8]. I. Nor Aini and S. Sabariah, Edible uses of palm kernel oil and its products, in Y. Basiron, A. Darus, M.A. Ngan, C.K.Weng (Eds.), Palm kernel products: characterisitics and applications, Kaulalumpur, Malaysian: Palm Oil Board, 2005, 95-118.

[9]. I. Nor Hayati, A. Aminah, S. Mamot, I. Nor Aini and H.M. Nor Lida, Physical characteristics of modified milk fat in high melting fat preparation, International Journal of Food Science and Nutrition, 53, 2002, 43-54.

[10]. K.A.G. Gopal, S. Khatoon and R. Babylatha, Frying performance of processed rice bran oils. Journal of Food Lipids, 12, 2005, 111.

[11]. P. T. Usha and B.R. Premi, Rice bran oil - Natures gift to mankind. www.Nabard.com, 7, 2011, 1-2.

[12]. K.A.G. Gopal, K.H. Hemakumar and S. Khatoon, Study on the composition of rice bran oil and its higher free fatty acids value. Journal of American Oil Chemist's Society, 83, 2006, 117-20.

[13]. S.A. Bhatnagar, K.P. Kumar, J. Hemavathy and G.A. Krishna, (2009). Fatty acid composition, oxidative stability and radical scavenging activity of vegetable oil blends with coconut oil. Journal of American Oil Chemist's Society, 86, 2009 991-99.

[14]. PFA, Prevention of Food Adulteration Act (11 $1^{\text {th }}$ Amendment) Rules, 2005. Ministry of Health and Family Welfare, Department of Health, G.S.R. 596€, $4^{\text {th }}$ Amendment- 1992, 1954, 1-13.

[15]. AOCS, Official Methods and Recommended Practices of the American Oil Chemists' Society, fourth ed. Champaign, Illinois: AOCS Press, 1990.

[16]. AOAC, Oils and Fats, in H. William (Ed.), Official Methods of Analysis of AOAC International, Maryland, USA: AOAC International, 2000, 1-69.

[17]. C. Tompkins and E.G.Perkins, Frying performance of low-linolenic acid soybean oil. Journal of American Oil Chemist's Society, 77, 2000, 223-9.

[18]. S. Bastida, F.J. Sanchez-Muniz, Thermal oxidation of olive oil, sunflower oil and a mix of both oils during forty discontinuous domestic fryings of different foods. Food Science Technology, 7, 2001, 15-21.

[19]. C. Gertz, C.U. Hagen, B. Matthäus, M. Rubner-Institut and Münster, Optimum deep frying: Recommendations by the German Society for Fat Science (DGF, Deutsche Gesellschaft für Fettwissenschaft e.V.). www.dgfett.de, 2008, 4-23.

[20]. D.G. Atinafu and B. Bedemo, Estimation of total free fatty acid and cholesterol content in some commercial edible oils in Ethiopia, Bahir DAR. Journal of Cereals Oilseeds, 2, 2011, 71-76.

[21]. A.G. Otunola, G.B. Adebayo and O.G. Olufemi, Evaluation of some physicochemical parameters of selected brands of vegetable oils sold in Ilorin metropolis. International Journal of Physical Sciences, 4, 2009, 327-329.

[22]. AOCS, Official Method Cd 8-53, Champaign, Illinois: AOCS Press. www.bioriginal.com, 2003.

[23]. N. Muhammad, E. Bamishaiye, O. Bamishaiye, L. Usman, M. Salawu, M. Nafiu and O. Oloyede, Physicochemical properties and fatty acid composition of cyperus esculentus (Tiger Nut) Tuber Oil. Bioresearch Bulletin, 5, 2011, 51-54.

[24]. H.M. Tamzid, M.T. Alam and M.A.U. Islam, Physico-chemical and nutritional studies of Terminalia belerica roxb. Seed oil and seed kernel. Journal of Biosciences, 15, 2007, 117-126. 
[25]. G.K. Berger, Frying oil series: The use of palm oil in frying. Selangor, Malaysia: Malaysian palm oil promotion council, 2005, 4113.

[26]. M.R. Sulieman, A.E. Makhzangy and M.F. Ramadan, Antiradical performance and physicochemical characterestics of vegetable oils upon frying of French fries: a preliminary comparative. Electronic Journal of Environment Agriculture and Food Chemistry, 5(4), 2006, 1429-1441.

[27]. Y. C. Tseng, R.G. Moreira and X. Sun, Total frying-use time effects on soybean oil deterioration and on tortilla chip quality. International Journal of Food Science and Technology, 31, 1996, 287- 94.

[28]. S. Gulla and K. Waghray, (2011). Effect of storage on physico-chemical characteristics and fatty acid composition of selected oil blends. Journal of Lipid Science, 3, 2011, 35-46.

[29]. Y. B. Che Man, C.P. Tan, I. Nor Aini, S.A.H. Nazimah and H.L. Gan, Characterization of vegetable oil by surface acoustic wave spending electric nose. Food Chemistry, 89, 2005, 507-518.

[30]. A. Serjouie, C.P. Tan, H. Mirhosseini and Y.B. Che Man, Effect of vegetable-based oil blends on physicochemical properties of oils during deep-fat frying. American Journal of Food Technology, 5, 2010, 310- 323.

[31]. S. Alireza, C.P. Tan, M. Hamed and Y.B. Che Man, Effect of frying process on fatty acid composition and iodine value of selected vegetable oils and their blends. Internatinal Food Research Journal, 17, 2010, 295-302.

[32]. P. Rastogi, B. Mathur, S. Rastogi, V.P. Gupta and R. Gupta, Fatty acid oxidation and other biochemical changes induced by cooking in commonly used Indian fats and oils. Nutrition and Food Science, 36, 2006, $407-413$.

[33]. CX - STAN, Codex standard for named vegetable oils. CODEX STAN 210-1999, 1999, 1-16.

[34]. A.D.Semwal and S.S. Arya, Studies on the stability of some edible oils and their blends during storage. Journal of Food Science and Technology, 38, 2001, 515-518.

[35]. I.O. Onigbogi and K.A. Sowunmi (2011). Impact of frying operations on the physical and chemical properties of groundnut oil. Journal of Applied and Environmental Science. http://japenvsci.com/index.php/japenvs/article/view/21

Table 1. Changes in fat absorption (\%) of rice bran oil blends during deep-fat frying

\begin{tabular}{|c|c|c|c|c|}
\hline \multicolumn{5}{|l|}{ Ratio 70:30 } \\
\hline \multirow[t]{2}{*}{ Blend } & \multicolumn{3}{|c|}{ Frying } & $\mathrm{CD}^{\circ}$ \\
\hline & I & II & III & \\
\hline $\mathrm{RBO}+\mathrm{OO}$ & $6.00 \pm 0.44$ & $9.57 \pm 0.32$ & $5.88 \pm 0.26$ & 1.52 \\
\hline $\mathrm{RBO}+\mathrm{GO}$ & $4.30 \pm 0.45$ & $7.00 \pm 0.39$ & $6.74 \pm 0.20$ & 1.42 \\
\hline $\mathrm{RBO}+\mathrm{SOO}$ & $8.50 \pm 0.39$ & $9.78 \pm 0.36$ & $3.61 \pm 0.44$ & 0.72 \\
\hline $\mathrm{RBO}+\mathrm{SO}$ & $7.40 \pm 0.57$ & $9.67 \pm 0.44$ & $10.80 \pm 0.25$ & 1.32 \\
\hline $\mathrm{RBO}+\mathrm{MO}$ & $8.00 \pm 0.25$ & $7.61 \pm 0.21$ & $7.20 \pm 0.32$ & 0.48 \\
\hline $\mathrm{RBO}+\mathrm{PO}$ & $10.00 \pm 0.26$ & $8.89 \pm 0.35$ & $7.32 \pm 0.44$ & 1.11 \\
\hline $\mathrm{CD}^{\bullet}$ & 1.35 & 1.25 & 1.34 & - \\
\hline \multicolumn{5}{|l|}{ Ratio 80:20 } \\
\hline $\mathrm{RBO}+\mathrm{OO}$ & $6.20 \pm 0.41$ & $10.4 \pm 0.29$ & $5.23 \pm 0.23$ & 1.32 \\
\hline $\mathrm{RBO}+\mathrm{GO}$ & $4.90 \pm 0.42$ & $7.42 \pm 0.36$ & $6.02 \pm 0.17$ & 1.52 \\
\hline $\mathrm{RBO}+\mathrm{SOO}$ & $8.89 \pm 0.36$ & $9.93 \pm 0.33$ & $4.02 \pm 0.41$ & 1.62 \\
\hline $\mathrm{RBO}+\mathrm{SO}$ & $7.64 \pm 0.54$ & $9.89 \pm 0.41$ & $10.71 \pm 0.23$ & 1.41 \\
\hline $\mathrm{RBO}+\mathrm{MO}$ & $8.42 \pm 0.22$ & $7.78 \pm 0.18$ & $7.42 \pm 0.29$ & 1.22 \\
\hline $\mathrm{RBO}+\mathrm{PO}$ & $10.63 \pm 0.23$ & $8.76 \pm 0.32$ & $7.63 \pm 0.41$ & 1.45 \\
\hline $\mathrm{CD}^{\bullet}$ & 1.25 & 1.35 & 1.43 & - \\
\hline
\end{tabular}

Values are expressed as mean $\pm \mathrm{SE}, \stackrel{\bullet}{=}$ Significant at $5 \%$

RBO rice bran oil, OO olive oil, GO groundnut oil, SOO soybean oil, SO sunflower oil, MO mustard oil, PO palm-olein oil

Table 2. Changes in physical parameters of rice bran oil blends during deep-fat frying Smoke point $\left({ }^{\circ} \mathrm{C}\right)$

\section{Ratio 70:30}

Blend

$\mathrm{RBO}+\mathrm{OO}$

$\mathrm{RBO}+\mathrm{GO}$

$\mathrm{RBO}+\mathrm{SOO}$

$\mathrm{RBO}+\mathrm{SO}$

$\mathrm{RBO}+\mathrm{MO}$

$\mathrm{RBO}+\mathrm{PO}$

$\mathrm{CD}^{\bullet}$

\section{Frying

$$
\text { II }
$$

$200 \pm 0.54$

$204 \pm 0.34$

$202 \pm 0.65$

$190 \pm 0.43$

$200 \pm 0.28$

$184 \pm 0.28$

1.57
$182 \pm 0.27$

$194 \pm 0.28$

$186 \pm 0.56$

$176 \pm 0.55$

$188 \pm 0.63$

$170 \pm 0.27$

1.77
$\mathrm{CD}^{\circ}$

III

$170 \pm 0.23$

1.63

$182 \pm 0.16$

$180 \pm 0.54$

$170 \pm 0.37$

$172 \pm 0.54$

$166 \pm 0.54$

1.50
1.48

2.30

1.88

1.88

1.63 


\begin{tabular}{lccccccc}
\hline & & & & & & & \\
RBO+OO & $200 \pm 0.52$ & $186 \pm 0.25$ & $174 \pm 0.21$ & 1.48 & 0 & 7.0 & 13.0 \\
RBO+GO & $202 \pm 0.32$ & $190 \pm 0.26$ & $178 \pm 0.14$ & 1.48 & 0 & 5.9 & 11.9 \\
RBO+SOO & $200 \pm 0.63$ & $184 \pm 0.54$ & $176 \pm 0.52$ & 1.48 & 0 & 8.0 & 12.0 \\
RBO+SO & $188 \pm 0.41$ & $174 \pm 0.53$ & $169 \pm 0.35$ & 1.33 & 0 & 7.4 & 10.1 \\
RBO+MO & $200 \pm 0.26$ & $182 \pm 0.61$ & $174 \pm 0.52$ & 0.95 & 0 & 9.0 & 13.0 \\
RBO+PO & $180 \pm 0.26$ & $174 \pm 0.25$ & $160 \pm 0.52$ & 1.88 & 0 & 3.3 & 11.1 \\
CD & 1.02 & 1.77 & 0.93 & - & - & - & -
\end{tabular}

Frying temperature $\left({ }^{\circ} \mathrm{C}\right)$

\section{Ratio 70:30}

Blend

$\begin{array}{lcc} & \text { I } \\ \text { RBO+OO } & 175 \pm 0.67 \\ \text { RBO+GO } & 170 \pm 0.45 \\ \text { RBO+SOO } & 182 \pm 0.39 \\ \text { RBO+SO } & 168 \pm 0.57 \\ \text { RBO+MO } & 174 \pm 0.25 \\ \text { RBO+PO } & 178 \pm 0.26 \\ \text { CD } & 1.87\end{array}$

\section{Ratio 80:20}

\begin{tabular}{lccccccc} 
RBO+OO & $177 \pm 0.64$ & $186 \pm 0.29$ & $189 \pm 0.23$ & 1.63 & 0 & 4.8 & 6.3 \\
RBO+GO & $174 \pm 0.42$ & $179 \pm 0.36$ & $186 \pm 0.17$ & 0.93 & 0 & 2.8 & 6.5 \\
RBO+SOO & $185 \pm 0.36$ & $189 \pm 0.33$ & $189 \pm 0.64$ & 1.88 & 0 & 2.1 & 2.1 \\
RBO+SO & $169 \pm 0.54$ & $176 \pm 0.30$ & $189 \pm 0.23$ & 1.33 & 0 & 4.0 & 10.6 \\
RBO+MO & $177 \pm 0.22$ & $184 \pm 0.18$ & $189 \pm 0.29$ & 1.48 & 0 & 3.8 & 6.3 \\
RBO+PO & $180 \pm 0.23$ & $186 \pm 0.32$ & $195 \pm 0.64$ & 1.99 & 0 & 3.2 & 7.7 \\
$\mathrm{CD}^{\bullet}$ & 1.32 & 1.22 & 1.57 & - & - & - & - \\
\hline
\end{tabular}

Values are expressed as mean $\pm \mathrm{SE}, \stackrel{\bullet}{=}$ Significant at $5 \%$

RBO rice bran oil, OO olive oil, GO groundnut oil, SOO soybean oil, SO sunflower oil, MO mustard oil, PO palm-olein oil

Table 3. Changes in viscosity (CST) of rice bran oil blends during deep-fat frying

\begin{tabular}{|c|c|c|c|c|c|c|c|c|}
\hline \multicolumn{9}{|l|}{ Ratio 70:30 } \\
\hline Blend & Fresh & \multicolumn{3}{|c|}{ Frying } & $\mathrm{CD}^{\circ}$ & \multicolumn{3}{|c|}{ Percent change after frying } \\
\hline $\mathrm{RBO}+\mathrm{OO}$ & $40 \pm 0.31$ & $\underset{41 \pm 0.34}{\text { I }}$ & $\underset{42.5 \pm 0.32}{\text { II }}$ & $\underset{44 \pm 0.36}{\text { III }}$ & 0.61 & $\begin{array}{c}\mathbf{I} \\
2.5\end{array}$ & $\begin{array}{c}\text { II } \\
6.3\end{array}$ & $\underset{10.0}{\text { III }}$ \\
\hline $\mathrm{RBO}+\mathrm{GO}$ & $39 \pm 0.24$ & $40 \pm 0.18$ & $42.5 \pm 0.26$ & $45 \pm 0.32$ & 0.47 & 2.6 & 9.0 & 15.4 \\
\hline $\mathrm{RBO}+\mathrm{SOO}$ & $35 \pm 0.37$ & $36 \pm 0.41$ & $37.5 \pm 0.24$ & $41 \pm 0.32$ & 0.61 & 2.9 & 7.1 & 17.1 \\
\hline $\mathrm{RBO}+\mathrm{SO}$ & $32 \pm 0.02$ & $33 \pm 0.25$ & $35 \pm 0.32$ & $39 \pm 0.28$ & 0.48 & 3.1 & 9.4 & 21.9 \\
\hline $\mathrm{RBO}+\mathrm{MO}$ & $37 \pm 0.32$ & $39 \pm 0.33$ & $42 \pm 0.30$ & $43.5 \pm 0.30$ & 0.59 & 5.4 & 13.5 & 17.6 \\
\hline $\mathrm{RBO}+\mathrm{PO}$ & $38 \pm 0.03$ & $40 \pm 0.32$ & $41 \pm 0.29$ & $44 \pm 0.30$ & 0.49 & 5.3 & 7.9 & 15.8 \\
\hline $\mathrm{CD}^{\bullet}$ & 0.44 & 0.53 & 0.54 & 0.54 & - & - & - & - \\
\hline \multicolumn{9}{|l|}{ Ratio 80:20 } \\
\hline $\mathrm{RBO}+\mathrm{OO}$ & $41 \pm 0.29$ & $42 \pm 0.15$ & $44 \pm 0.21$ & $45 \pm 0.31$ & 0.45 & 2.4 & 7.3 & 9.8 \\
\hline $\mathrm{RBO}+\mathrm{GO}$ & $40 \pm 0.24$ & $41 \pm 0.31$ & $43 \pm 0.31$ & $44 \pm 0.15$ & 0.48 & 2.5 & 7.5 & 10.0 \\
\hline $\mathrm{RBO}+\mathrm{SOO}$ & $36 \pm 0.10$ & $37 \pm 0.10$ & $39 \pm 0.22$ & $41 \pm 0.22$ & 0.30 & 2.8 & 8.3 & 13.9 \\
\hline $\mathrm{RBO}+\mathrm{SO}$ & $31 \pm 0.22$ & $33 \pm 0.10$ & $36 \pm 0.11$ & $38 \pm 0.10$ & 0.25 & 6.5 & 16.1 & 22.6 \\
\hline $\mathrm{RBO}+\mathrm{MO}$ & $38 \pm 0.31$ & $40 \pm 0.31$ & $42 \pm 0.07$ & $43.5 \pm 0.15$ & 0.44 & 5.3 & 10.5 & 14.5 \\
\hline $\mathrm{RBO}+\mathrm{PO}$ & $39 \pm 0.18$ & $41 \pm 0.06$ & $42.5 \pm 0.12$ & $44 \pm 0.15$ & 0.25 & 5.1 & 9.0 & 12.8 \\
\hline $\mathrm{CD}^{\bullet}$ & 0.41 & 0.35 & 0.33 & 0.33 & - & - & - & - \\
\hline
\end{tabular}

Values are expressed as mean $\pm \mathrm{SE}, \stackrel{\bullet}{=}$ Significant at $5 \%$

RBO rice bran oil, OO olive oil, GO groundnut oil, SOO soybean oil, SO sunflower oil, MO mustard oil, PO palm-olein oil 
Table 4. Changes in peroxide and iodine value of rice bran oil blends during deep-fat frying

\begin{tabular}{|c|c|c|c|c|c|c|c|c|}
\hline \multicolumn{9}{|c|}{ Peroxide value (meq/Kg) } \\
\hline \multicolumn{9}{|l|}{ Ratio 70:30 } \\
\hline \multirow[t]{2}{*}{ Blend } & \multirow[t]{2}{*}{ Fresh } & \multicolumn{3}{|c|}{ Frying } & \multirow[t]{2}{*}{$\mathrm{CD}^{\bullet}$} & \multicolumn{3}{|c|}{ Percent change after frying } \\
\hline & & $\mathbf{I}$ & II & III & & I & II & III \\
\hline $\mathrm{RBO}+\mathrm{OO}$ & $0.53 \pm 0.07$ & $1.13 \pm 0.05$ & $2.33 \pm 0.06$ & $2.93 \pm 0.07$ & 0.60 & 53.1 & 77.3 & 81.9 \\
\hline $\mathrm{RBO}+\mathrm{GO}$ & $1.53 \pm 0.07$ & $2.40 \pm 0.00$ & $2.93 \pm 0.07$ & $3.47 \pm 0.13$ & 0.46 & 36.3 & 47.8 & 55.9 \\
\hline $\mathrm{RBO}+\mathrm{SOO}$ & $1.40 \pm 0.00$ & $1.73 \pm 0.07$ & $3.53 \pm 0.07$ & $6.13 \pm 0.07$ & 0.32 & 19.1 & 60.3 & 77.2 \\
\hline $\mathrm{RBO}+\mathrm{SO}$ & $0.93 \pm 0.07$ & $1.60 \pm 0.00$ & $3.13 \pm 0.07$ & $6.47 \pm 0.13$ & 0.45 & 41.9 & 70.3 & 85.6 \\
\hline $\mathrm{RBO}+\mathrm{MO}$ & $1.73 \pm 0.07$ & $2.13 \pm 0.07$ & $4.53 \pm 0.07$ & $5.80 \pm 0.00$ & 0.35 & 18.8 & 61.8 & 70.2 \\
\hline $\mathrm{RBO}+\mathrm{PO}$ & $1.47 \pm 0.07$ & $1.80 \pm 0.00$ & $2.13 \pm 0.07$ & $5.73 \pm 0.07$ & 0.36 & 18.3 & 31.0 & 74.3 \\
\hline $\mathrm{CD}^{\bullet}$ & 0.54 & 0.34 & 0.35 & 0.38 & - & - & - & - \\
\hline \multicolumn{9}{|l|}{ Ratio 80:20 } \\
\hline $\mathrm{RBO}+\mathrm{OO}$ & $0.33 \pm 0.07$ & $0.93 \pm 0.07$ & $1.80 \pm 0.00$ & $2.53 \pm 0.07$ & 0.69 & 64.5 & 81.7 & 87.0 \\
\hline $\mathrm{RBO}+\mathrm{GO}$ & $1.13 \pm 0.07$ & $1.73 \pm 0.02$ & $2.53 \pm 0.06$ & $3.13 \pm 0.07$ & 0.46 & 34.7 & 55.3 & 63.9 \\
\hline $\mathrm{RBO}+\mathrm{SOO}$ & $1.38 \pm 0.06$ & $1.53 \pm 0.04$ & $2.73 \pm 0.07$ & $4.87 \pm 0.13$ & 0.52 & 9.8 & 49.5 & 71.7 \\
\hline $\mathrm{RBO}+\mathrm{SO}$ & $0.73 \pm 0.03$ & $1.33 \pm 0.05$ & $2.73 \pm 0.07$ & $4.73 \pm 0.09$ & 0.52 & 45.1 & 73.3 & 84.6 \\
\hline $\mathrm{RBO}+\mathrm{MO}$ & $1.33 \pm 0.06$ & $1.73 \pm 0.08$ & $3.93 \pm 0.07$ & $5.13 \pm 0.06$ & 0.42 & 23.1 & 66.2 & 74.1 \\
\hline $\mathrm{RBO}+\mathrm{PO}$ & $1.10 \pm 0.08$ & $1.33 \pm 0.07$ & $1.73 \pm 0.07$ & $4.40 \pm 0.00$ & 0.47 & 17.3 & 36.4 & 75.0 \\
\hline $\mathrm{CD}^{\bullet}$ & 0.69 & 0.51 & 0.34 & 0.34 & - & - & - & - \\
\hline \multicolumn{9}{|c|}{ Iodine value (g) } \\
\hline \multicolumn{9}{|l|}{ Ratio 70:30 } \\
\hline \multirow[t]{2}{*}{ Blend } & \multirow[t]{2}{*}{ Fresh } & \multicolumn{3}{|c|}{ Frying } & $\mathrm{CD}^{\bullet}$ & \multicolumn{3}{|c|}{ Percent change after frying } \\
\hline & & I & II & III & & I & II & III \\
\hline $\mathrm{RBO}+\mathrm{OO}$ & $114.6 \pm 0.08$ & $113.7 \pm 0.31$ & $112.1 \pm 0.16$ & $110.2 \pm 0.09$ & 0.43 & 0.8 & 2.2 & 3.8 \\
\hline $\mathrm{RBO}+\mathrm{GO}$ & $113.4 \pm 0.08$ & $109.6 \pm 0.08$ & $108.4 \pm 0.09$ & $106.1 \pm 0.34$ & 0.40 & 3.4 & 4.4 & 6.4 \\
\hline $\mathrm{RBO}+\mathrm{SOO}$ & $112.5 \pm 0.00$ & $111.3 \pm 0.08$ & $109.6 \pm 0.16$ & $108.4 \pm 0.09$ & 0.22 & 1.1 & 2.6 & 3.6 \\
\hline $\mathrm{RBO}+\mathrm{SO}$ & $117.0 \pm 0.08$ & $110.1 \pm 0.08$ & $107.0 \pm 0.09$ & $104.5 \pm 0.09$ & 0.29 & 5.9 & 8.5 & 10.7 \\
\hline $\mathrm{RBO}+\mathrm{MO}$ & $115.1 \pm 0.08$ & $111.6 \pm 0.09$ & $109.4 \pm 0.16$ & $107.0 \pm 0.09$ & 0.25 & 3.0 & 5.0 & 7.0 \\
\hline $\mathrm{RBO}+\mathrm{PO}$ & $107.3 \pm 0.09$ & $105.6 \pm 0.09$ & $104.3 \pm 0.09$ & $104.4 \pm 0.29$ & 0.23 & 1.6 & 2.8 & 2.7 \\
\hline $\mathrm{CD}^{\bullet}$ & 0.22 & 0.33 & 0.28 & 0.34 & - & - & - & - \\
\hline \multicolumn{9}{|l|}{ Ratio 80:20 } \\
\hline $\mathrm{RBO}+\mathrm{OO}$ & $115.2 \pm 0.08$ & $108.4 \pm 0.08$ & $105.7 \pm 0.25$ & $104.2 \pm 0.16$ & 0.36 & 5.9 & 8.2 & 9.5 \\
\hline $\mathrm{RBO}+\mathrm{GO}$ & $113.2 \pm 0.16$ & $111.3 \pm 0.00$ & $109.6 \pm 0.08$ & $106.5 \pm 0.08$ & 0.23 & 1.7 & 3.2 & 5.9 \\
\hline $\mathrm{RBO}+\mathrm{SOO}$ & $115.7 \pm 0.08$ & $112.4 \pm 0.09$ & $110.2 \pm 0.16$ & $108.8 \pm 0.08$ & 0.24 & 2.9 & 4.8 & 6.0 \\
\hline $\mathrm{RBO}+\mathrm{SO}$ & $118.9 \pm 0.16$ & $115.8 \pm 0.08$ & $110.2 \pm 0.00$ & $106.5 \pm 0.05$ & 0.28 & 2.6 & 7.3 & 10.4 \\
\hline $\mathrm{RBO}+\mathrm{MO}$ & $114.7 \pm 0.08$ & $114.2 \pm 0.08$ & $110.9 \pm 0.16$ & $107.8 \pm 0.08$ & 0.26 & 0.4 & 3.3 & 6.0 \\
\hline $\mathrm{RBO}+\mathrm{PO}$ & $107.0 \pm 0.08$ & $105.6 \pm 0.09$ & $100.7 \pm 0.34$ & $102.2 \pm 0.09$ & 0.36 & 1.3 & 5.9 & 4.5 \\
\hline $\mathrm{CD}^{\bullet}$ & 0.29 & 0.16 & 0.39 & 0.20 & - & - & - & - \\
\hline
\end{tabular}

Values are expressed as mean $\pm \mathrm{SE}, \stackrel{\bullet}{=}$ Significant at $5 \%$

RBO rice bran oil, OO olive oil, GO groundnut oil, SOO soybean oil, SO sunflower oil, MO mustard oil, PO palm-olein oil 
Effect of Deep-Fat Frying on Physicochemical Properties of Rice Bran Oil Blends

Table 5. Changes in acid value and free fatty acids of rice bran oil blends during deep-fat frying

\begin{tabular}{|c|c|c|c|c|c|c|c|c|}
\hline \multicolumn{9}{|c|}{ Acid value (mg KOH/g) } \\
\hline \multicolumn{9}{|l|}{ Ratio 70:30 } \\
\hline Blend & Fresh & & Frying & & $\mathrm{CD}^{\bullet}$ & Percen & hange & after frying \\
\hline $\mathrm{RBO}+\mathrm{OO}$ & $0.19 \pm 0.05$ & $\begin{array}{c}\mathbf{I} \\
0.37 \pm 0.05\end{array}$ & $\underset{0.42 \pm 0.00}{\text { II }}$ & $\underset{0.51 \pm 0.05}{\text { III }}$ & 0.68 & $\begin{array}{c}\text { I } \\
48.6\end{array}$ & $\underset{54.8}{\text { II }}$ & $\begin{array}{l}\text { III } \\
62.7\end{array}$ \\
\hline $\mathrm{RBO}+\mathrm{GO}$ & $0.37 \pm 0.05$ & $0.65 \pm 0.05$ & $0.56 \pm 0.08$ & $0.37 \pm 0.05$ & 0.78 & 43.1 & 33.9 & 0.0 \\
\hline $\mathrm{RBO}+\mathrm{SOO}$ & $0.22 \pm 0.00$ & $0.37 \pm 0.05$ & $0.65 \pm 0.05$ & $0.47 \pm 0.09$ & 0.58 & 40.5 & 66.2 & 53.2 \\
\hline $\mathrm{RBO}+\mathrm{SO}$ & $0.23 \pm 0.05$ & $0.28 \pm 0.00$ & $0.28 \pm 0.00$ & $0.37 \pm 0.05$ & 0.64 & 17.9 & 17.9 & 37.8 \\
\hline RBO+MO & $0.28 \pm 0.00$ & $0.51 \pm 0.05$ & $0.33 \pm 0.09$ & $0.65 \pm 0.05$ & 0.95 & 45.1 & 15.2 & 56.9 \\
\hline $\mathrm{RBO}+\mathrm{PO}$ & $0.42 \pm 0.00$ & $0.42 \pm 0.14$ & $0.42 \pm 0.00$ & $0.56 \pm 0.00$ & 0.79 & 0.0 & 0.0 & 25.0 \\
\hline $\mathrm{CD}^{\bullet}$ & 0.60 & 0.57 & 0.79 & 0.79 & - & - & - & - \\
\hline \multicolumn{9}{|l|}{ Ratio 80:20 } \\
\hline $\mathrm{RBO}+\mathrm{OO}$ & $0.28 \pm 0.00$ & $0.51 \pm 0.05$ & $0.42 \pm 0.00$ & $0.61 \pm 0.05$ & 0.41 & 45.1 & 33.3 & 54.1 \\
\hline $\mathrm{RBO}+\mathrm{GO}$ & $0.23 \pm 0.05$ & $0.42 \pm 0.05$ & $0.23 \pm 0.05$ & $0.58 \pm 0.05$ & 0.73 & 45.2 & 0.0 & 60.3 \\
\hline $\mathrm{RBO}+\mathrm{SOO}$ & $0.19 \pm 0.05$ & $0.61 \pm 0.05$ & $0.42 \pm 0.00$ & $0.56 \pm 0.09$ & 0.62 & 68.9 & 54.8 & 66.1 \\
\hline $\mathrm{RBO}+\mathrm{SO}$ & $0.28 \pm 0.00$ & $0.47 \pm 0.09$ & $0.33 \pm 0.09$ & $0.61 \pm 0.05$ & 0.58 & 40.4 & 15.2 & 54.1 \\
\hline RBO+MO & $0.24 \pm 0.08$ & $0.37 \pm 0.05$ & $0.61 \pm 0.05$ & $0.56 \pm 0.00$ & 0.87 & 35.1 & 60.7 & 57.1 \\
\hline $\mathrm{RBO}+\mathrm{PO}$ & $0.37 \pm 0.05$ & $0.56 \pm 0.00$ & $0.47 \pm 0.09$ & $0.33 \pm 0.09$ & 0.65 & 33.9 & 21.3 & 12.1 \\
\hline $\mathrm{CD}^{\bullet}$ & 0.87 & 0.77 & 0.94 & 0.78 & - & - & - & - \\
\hline
\end{tabular}

Free fatty acids $(\%)$

Ratio 70:30

\begin{tabular}{|c|c|c|c|c|c|c|c|c|}
\hline \multirow[t]{2}{*}{ Blend } & \multirow[t]{2}{*}{ Fresh } & \multicolumn{3}{|c|}{ Frying } & \multirow[t]{2}{*}{$\mathrm{CD}^{\bullet}$} & \multicolumn{2}{|c|}{ Percent change } & \multirow{2}{*}{$\begin{array}{c}\text { after frying } \\
\text { III }\end{array}$} \\
\hline & & $\mathbf{I}$ & II & III & & $\mathbf{I}$ & II & \\
\hline $\mathrm{RBO}+\mathrm{OO}$ & $0.09 \pm 0.02$ & $0.19 \pm 0.02$ & $0.21 \pm 0.00$ & $0.26 \pm 0.02$ & 0.38 & 52.6 & 57.1 & 65.4 \\
\hline $\mathrm{RBO}+\mathrm{GO}$ & $0.19 \pm 0.02$ & $0.33 \pm 0.02$ & $0.28 \pm 0.04$ & $0.19 \pm 0.02$ & 0.55 & 42.4 & 32.1 & 0.0 \\
\hline $\mathrm{RBO}+\mathrm{SOO}$ & $0.11 \pm 0.00$ & $0.19 \pm 0.02$ & $0.33 \pm 0.02$ & $0.24 \pm 0.05$ & 0.46 & 42.1 & 66.7 & 54.2 \\
\hline $\mathrm{RBO}+\mathrm{SO}$ & $0.12 \pm 0.02$ & $0.14 \pm 0.00$ & $0.14 \pm 0.00$ & $0.19 \pm 0.02$ & 0.58 & 14.3 & 14.3 & 36.8 \\
\hline $\mathrm{RBO}+\mathrm{MO}$ & $0.14 \pm 0.00$ & $0.26 \pm 0.02$ & $0.16 \pm 0.08$ & $0.33 \pm 0.02$ & 0.53 & 46.2 & 12.5 & 57.6 \\
\hline $\mathrm{RBO}+\mathrm{PO}$ & $0.21 \pm 0.00$ & $0.21 \pm 0.04$ & $0.21 \pm 0.00$ & $0.28 \pm 0.00$ & 0.64 & 0.0 & 0.0 & 25.0 \\
\hline $\mathrm{CD}^{\bullet}$ & 0.28 & 0.62 & 0.46 & 0.52 & - & - & - & - \\
\hline \multicolumn{9}{|l|}{ Ratio 80:20 } \\
\hline $\mathrm{RBO}+\mathrm{OO}$ & $0.14 \pm 0.00$ & $0.26 \pm 0.02$ & $0.21 \pm 0.00$ & $0.31 \pm 0.02$ & 0.29 & 46.2 & 33.3 & 54.8 \\
\hline $\mathrm{RBO}+\mathrm{GO}$ & $0.12 \pm 0.02$ & $0.21 \pm 0.00$ & $0.12 \pm 0.02$ & $0.29 \pm 0.02$ & 0.32 & 42.9 & 0.0 & 58.6 \\
\hline $\mathrm{RBO}+\mathrm{SOO}$ & $0.09 \pm 0.02$ & $0.31 \pm 0.04$ & $0.21 \pm 0.00$ & $0.28 \pm 0.02$ & 0.32 & 71.0 & 57.1 & 67.9 \\
\hline $\mathrm{RBO}+\mathrm{SO}$ & $0.14 \pm 0.00$ & $0.24 \pm 0.05$ & $0.16 \pm 0.05$ & $0.31 \pm 0.02$ & 0.68 & 41.7 & 12.5 & 54.8 \\
\hline $\mathrm{RBO}+\mathrm{MO}$ & $0.12 \pm 0.05$ & $0.19 \pm 0.04$ & $0.31 \pm 0.04$ & $0.28 \pm 0.00$ & 0.50 & 36.8 & 61.3 & 57.1 \\
\hline $\mathrm{RBO}+\mathrm{PO}$ & $0.19 \pm 0.02$ & $0.28 \pm 0.00$ & $0.24 \pm 0.02$ & $0.16 \pm 0.05$ & 0.45 & 32.1 & 20.8 & 18.8 \\
\hline $\mathrm{CD}^{\bullet}$ & 0.54 & 0.67 & 0.54 & 0.45 & - & - & - & - \\
\hline
\end{tabular}

Values are expressed as mean $\pm \mathrm{SE},{ }^{\circ}=$ Significant at $5 \%$

RBO rice bran oil, OO olive oil, GO groundnut oil, SOO soybean oil, SO sunflower oil, MO mustard oil, PO palm-olein oil 
Table 6. Changes in saponification value of rice bran oil blends during deep-fat frying

\begin{tabular}{|c|c|c|c|c|c|c|c|c|}
\hline \multicolumn{9}{|c|}{ Saponification value (mg $\mathrm{KOH} / \mathrm{g})$} \\
\hline \multicolumn{9}{|l|}{ Ratio 70:30 } \\
\hline \multirow[t]{2}{*}{ Blend } & \multirow[t]{2}{*}{ Fresh } & \multicolumn{3}{|c|}{ Frying } & \multirow[t]{2}{*}{$\mathrm{CD}^{\bullet}$} & \multirow{2}{*}{$\begin{array}{l}\text { Percent } \\
\text { I }\end{array}$} & \multicolumn{2}{|c|}{ change after frying } \\
\hline & & I & II & III & & & II & III \\
\hline $\mathrm{RBO}+\mathrm{OO}$ & $188.5 \pm 0.94$ & $158.7 \pm 1.86$ & $126.9 \pm 0.94$ & $109.2 \pm 1.61$ & 4.56 & 15.8 & 32.7 & 42.1 \\
\hline $\mathrm{RBO}+\mathrm{GO}$ & $194.1 \pm 1.86$ & $164.3 \pm 0.94$ & $113.9 \pm 0.94$ & $85.9 \pm 0.94$ & 4.02 & 15.4 & 41.3 & 55.7 \\
\hline $\mathrm{RBO}+\mathrm{SOO}$ & $184.1 \pm 0.94$ & $130.7 \pm 1.86$ & $88.7 \pm 1.86$ & $65.3 \pm 0.92$ & 4.81 & 29.0 & 51.8 & 64.5 \\
\hline $\mathrm{RBO}+\mathrm{SO}$ & $210.9 \pm 0.93$ & $161.5 \pm 1.86$ & $131.6 \pm 1.20$ & $104.5 \pm 0.94$ & 10.21 & 23.4 & 37.6 & 50.5 \\
\hline $\mathrm{RBO}+\mathrm{MO}$ & $224.0 \pm 0.00$ & $173.6 \pm 0.00$ & $115.7 \pm 1.86$ & $100.8 \pm 2.80$ & 5.49 & 22.5 & 48.3 & 55.0 \\
\hline $\mathrm{RBO}+\mathrm{PO}$ & $329.5 \pm 0.94$ & $253.9 \pm 0.93$ & $197.9 \pm 1.86$ & $133.5 \pm 0.93$ & 4.03 & 22.9 & 39.9 & 59.5 \\
\hline $\mathrm{CD}^{\bullet}$ & 3.32 & 4.39 & 8.55 & 4.69 & - & - & - & - \\
\hline \multicolumn{9}{|l|}{ Ratio 80:20 } \\
\hline $\mathrm{RBO}+\mathrm{OO}$ & $177.3 \pm 0.93$ & $167.1 \pm 0.93$ & $135.3 \pm 0.94$ & $110.1 \pm 1.86$ & 4.03 & 5.8 & 23.7 & 37.9 \\
\hline $\mathrm{RBO}+\mathrm{GO}$ & $190.9 \pm 0.93$ & $127.9 \pm 1.86$ & $98.9 \pm 0.93$ & $82.1 \pm 0.94$ & 4.02 & 33.0 & 48.2 & 57.0 \\
\hline $\mathrm{RBO}+\mathrm{SOO}$ & $174.5 \pm 0.93$ & $138.1 \pm 0.94$ & $110.1 \pm 0.93$ & $76.5 \pm 1.86$ & 4.34 & 20.9 & 36.9 & 56.2 \\
\hline $\mathrm{RBO}+\mathrm{SO}$ & $192.3 \pm 1.86$ & $158.7 \pm 0.94$ & $113.9 \pm 0.93$ & $85.9 \pm 0.93$ & 4.03 & 17.5 & 40.8 & 55.3 \\
\hline $\mathrm{RBO}+\mathrm{MO}$ & $199.7 \pm 0.94$ & $161.5 \pm 0.93$ & $108.3 \pm 0.94$ & $74.7 \pm 0.15$ & 15.45 & 19.1 & 45.8 & 62.6 \\
\hline $\mathrm{RBO}+\mathrm{PO}$ & $285.6 \pm 0.00$ & $241.7 \pm 3.73$ & $167.13 \pm 1.86$ & $108.3 \pm 1.86$ & 7.46 & 15.4 & 41.5 & 62.1 \\
\hline $\mathrm{CD}^{\bullet}$ & 3.32 & 5.75 & 3.52 & 12.53 & - & - & - & - \\
\hline
\end{tabular}

Values are expressed as mean $\pm \mathrm{SE},{ }^{\circ}=$ Significant at $5 \%$

RBO rice bran oil, OO olive oil, GO groundnut oil, SOO soybean oil, SO sunflower oil, MO mustard oil, PO palm-olein oil 